\title{
Controlando a Atividade Policial: uma análise comparada dos códigos de conduta no Brasil e Canadá 1
}

ARTHUR TRINDADE*

MARIA STELA GROSSI PORTO

\section{Resumo:}

Neste texto discutimos os códigos de deontologia policial em uso em duas instituições policiais: a Polícia Militar do Distrito Federal (Brasil) e o Ottawa Police Service (Canadá). Inicialmente, analisamos e comparamos os conteúdos destes documentos. A seguir, verificamos como cada uma destas duas instituições policiais articula seus sistemas de treinamento e avaliação com seus respectivos códigos de deontologia. Por fim, concluímos que a simples existência de códigos de deontologia, sem normas administrativas, não assegura o controle adequado das atividades policiais. Também constatamos a necessidade de assimilação destes códigos e normas administrativas pelos sistemas de treinamento e avaliação das polícias.

Palavras-chave: Polícia. Instituições policiais. Atividade policial. Ética policial. Códigos de conduta. Deontologia.

\footnotetext{
1 Esta pesquisa foi financiada pela Secretaria Nacional de Segurança Pública do Ministério da Justiça.

* Arthur Trindade é professor do Departamento de Sociologia da Universidade de Brasília e coordenador do Núcleo de Estudos sobre Violência e Segurança - NEVIS/UnB.

** Maria Stela Grossi Porto é professora do Departamento de Sociologia da Universidade de Brasília, vice-coordenadora do NEVIS e Líder do Grupo de Pesquisa em Violência e Segurança do Diretório de pesquisa do CNPq.
} 


\section{Introdução}

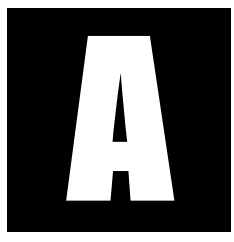

relação entre as polícias e a comunidade tem sido objeto de debate nas sociedades democráticas. As instituições policiais são aquelas organizações destinadas ao controle social com autorização para utilizar a força, caso necessário (Bayley, 1975). Nos regimes democráticos, a atividade policial requer um equilíbrio entre o uso da força e o respeito aos direitos individuais. Assim, podemos afirmar que a especificidade da atividade policial nos regimes democráticos é a necessidade de limitar e administrar o uso da força legal, sem abrir mão de suas prerrogativas de controle social.

Diversos países têm enfrentado o desafio de limitar e controlar a atividade policial. Basicamente, os esforços se concentraram na criação de mecanismos institucionais de responsabilização e controle. Entretanto, a qualidade e eficácia desses mecanismos, que visam inibir a violência, a brutalidade e a arbitrariedade policial, são questões ainda pouco problematizadas, tanto no interior das próprias polícias quanto fora delas, pelos pesquisadores. Além de fatores internos à organização policial, a análise e a compreensão de tais questões passa, igualmente, pelas relações entre polícia e sociedade.

Nas últimas décadas, vários países criaram códigos de deontologia e normas de conduta visando aumentar o controle sobre a atividade policial cotidiana. Em todos os casos, a adoção destes códigos e normas implicou em transformações no treinamento e na supervisão da atividade policial (Lint, 1998; Das e Palmiotto, 2002). Resta saber como a experiência policial pôde ser transformada em códigos de deontologia e normas de conduta, bem como perceber seus efeitos sobre o sistema de treinamento e avaliação das polícias.

Neste texto discutimos os códigos de deontologia policial em uso em duas instituições policiais: a Polícia Militar do Distrito Federal (Brasil) e o 
Ottawa Police Service (Canadá). Inicialmente, analisamos e comparamos os conteúdos destes documentos. A seguir, verificamos como cada uma destas duas instituições policiais articula seus sistemas de treinamento e avaliação com seus respectivos códigos de deontologia. Por fim, concluímos que a simples existência de códigos de deontologia, sem normas administrativas, não assegura o controle adequado das atividades policiais. Também constatamos a necessidade de assimilação destes códigos e normas administrativas pelos sistemas de treinamento e avaliação das polícias.

\section{A Pesquisa}

Ao adotar o método comparado para analisar os mecanismos internos de controle da atividade policial existentes nas duas diferentes instituições mencionadas, a Policia Militar do Distrito Federal (PMDF), no Brasil, e o Ottawa Police Service (OPS) do Canadá, o trabalho não pretendeu tomar nenhum sistema policial como um modelo a ser seguido. A comparação, neste caso, serviu apenas para esclarecer aspectos ainda não conhecidos sobre os conteúdos e os processos de implantação dos códigos de deontologia e das normas de conduta, além de as verificar especificidades e os aspectos comuns aos diferentes sistemas policiais dos dois países analisados.

Como nossos objetos de pesquisa foram os códigos de deontologia e as normas de conduta existentes nas polícias, optamos por comparar diferentes instituições policiais, e não cidades ou sociedades. Obviamente, ao fazer isso, não deixamos de considerar que o contexto social e político desempenha papel importante no condicionamento das dinâmicas e estruturas internas de cada instituição policial.

Para o levantamento de dados foram coletados códigos de deontologia e manuais de instrução utilizados nas duas instituições policiais. Também foram realizadas entrevistas com policiais brasileiros e canadenses envolvi- 
dos nas atividades de treinamento, avaliação e controle. Ao todo, foram entrevistados 27 policiais militares, de ambos os sexos, 09 no Canadá e 18 no Brasil. No Distrito Federal, foram ouvidos dirigentes, instrutores e alunos da Academia de Polícia e do Centro de Formação e Aperfeiçoamento de Praças, oficiais da Divisão de Ensino e da Corregedoria de Polícia Militar. Em Ottawa, foram entrevistados policiais da Professional Standards Unit, da Policy Development Unit e do Professional Development Centre.

\section{Códigos de Deontologia e Normas de Conduta}

Nos os estudos que buscaram entender os padrões de relacionamento entre a polícia e a sociedade, dois temas têm sido destacados: as formas de reforçar os vínculos entre a polícia e a comunidade e a necessidade de controlar a atividade das polícias. (Bayley, 1994; Geller e Toch, 1996; Skolnick e Fyfe,1993; Monjardet, 2003). Com relação a esse último, há um debate sobre a eficácia de alguns dos principais mecanismos de controle da atividade policial, a saber: ouvidorias, corregedorias, sistemas de supervisão, procuradorias especializadas (Costa, 2004). Aqui nos interessou discutir limites e potencialidades de um desses mecanismos: os Códigos de Deontologia.

O conceito de deontologia refere-se à idéia de controlar as atividades de determinados profissionais através da auto-imposição de deveres. Toda profissão impõe deveres e responsabilidades a quem a exerce. A deontologia é, etimologicamente, a ciência dos deveres. Portanto, a deontologia coloca-se como uma estratégia de propor e de transmitir uma ética, cujo objetivo é fazer com que os integrantes de uma profissão predisponham-se a aderir a um sistema de valores que associe eficácia e respeito pelas pessoas e pelas liberdades fundamentais, dentro e fora do exercício de sua profissão. Diferencia-se do direito no sentido de que as normas que propõe são internas. Muitas das regras previstas nos Códigos 
de Deontologia se sobrepõem às normas de conduta profissional e às regras jurídicas, resultando, portanto, num sistema complexo de controle profissional (Bandeira e Costa, 2003).

No que diz respeito às polícias, os códigos de deontologia estabelecem as regras e as obrigações essenciais ao trabalho dos policiais, inscrevendo-se num quadro jurídico de referência que define com precisão a natureza das modalidades da ação policial. Em outras palavras: os códigos de deontologia determinam os princípios e valores que devem nortear as atitudes e o comportamento que os policiais devem assumir dentro da corporação e na sua relação com o público.

Convém lembrar que, na maioria dos países em que o código de deontologia foi criado, objetivou-se modificar as concepções tradicionais da prática policial, sobretudo em relação à discricionariedade atribuída à prática profissional. Em relação ao código, é interessante fazer um paralelo entre os policiais e os profissionais liberais. Foram estes últimos - médicos, jornalistas e advogados - que sentiram a necessidade de estabelecer regras de deontologia para "delimitar" (circunscrever) suas práticas profissionais. Estes profissionais, embora respeitassem os regulamentos e as regras estabelecidas para o exercício da profissão, ao exercê-la livremente, tinham como respaldo apenas a confiança de seus pacientes e clientes. Não estavam submetidos a nenhum poder ou estrutura hierárquica como os policiais. No entanto, sentiram a necessidade de criar alguns limites suplementares a sua prática profissional. O policial, ao contrário dos profissionais liberais, desempenha suas funções demarcado por uma rígida estrutura hierárquica, embora nem sempre essa estrutura seja considerada, principalmente nas situações de patrulhamento de rua.

Apesar das diferenças quanto à estrutura hierárquica, podemos notar algumas semelhanças no exercício de tais profissões. Se compararmos os dois grupos, observa-se, frequentemente, que o cliente de um profissional liberal se encontra numa situação de dependência frente a este; é 
o caso do paciente com seu cirurgião, por exemplo. Este no momento da cirurgia, é o único mestre do ato, da decisão a ser tomada, pois apenas seus conhecimentos técnicos podem conduzi-lo. Em caso de situações extremas, contará apenas com sua ética profissional. Se deslocarmos essa problemática para a função do policial, constataremos que este, na sua prática cotidiana, agirá freqüentemente fora da estrutura hierárquica, dispondo de grande autonomia de ação. Nessa prática, os policiais não necessariamente regem suas ações pelo regulamento, leis ou normas de conduta. Guiam-se, no geral, pelo que denominam como 'sua própria experiência'. A existência dessa margem de iniciativa da ação do policial constitui-se exatamente no espaço que deve ser ocupado pela deontologia. Portanto, instituir um código de deontologia significa reconhecer, concomitantemente, a responsabilidade e a autonomia do policial.

Entretanto, pouco se sabe sobre as diferentes dinâmicas sociais, políticas e institucionais para a implantação dos códigos de deontologia policial. A partir de 1980, constatou-se o crescimento dos estudos sobre as polícias, constituindo-se no que Kant de Lima, Misse e Miranda (2000) denominaram de sociologia da organização policial contemporânea. Apesar dos esforços, pouco se avançou na compreensão dos mecanismos de controle da atividade policial, de seus instrumentos de controle e avaliação, bem como das dificuldades políticas, culturais e institucionais para sua implantação.

Sem uma clara diferenciação entre violência policial e uso da força legal não é possível estabelecer mecanismos destinados ao controle e supervisão das atividades policiais. Até que ponto e sob que circunstâncias é legítimo ou admissível o uso da força? Qual é a linha demarcatória entre força legítima e violência policial? Estas questões têm sido debatidas pela literatura especializada (Klockars, 1996; Muniz et alii, 1997; Mesquita Neto, 1999; Costa, 2003; Costa e Medeiros 2002; Porto, 2000; Adorno, 2002). Os estudos destacam que essa linha demarcatória não é fixa. O limite entre força legítima e violência varia em função da forma como cada 
sociedade interpreta a noção de violência e representa a função policial. No contexto brasileiro, além de insistir na necessidade de incrementar a educação e o treinamento, os depoimentos ressaltam a dificuldade em traduzir para a atividade prática os princípios mais teóricos disponíveis, seja em manuais de procedimentos operacionais, seja através da cultura oral.

Em Ottawa, a ênfase repousa, sobretudo, na possibilidade de o policial justificar seus atos, apoiado em leis ou códigos. A ação que pode ser assim justificada não é percebida como violência policial.

Vejamos como os entrevistados do Distrito Federal definem e delimitam as distinções entre força física e violência policial:

(...) algemar e conseguir incapacitar, isso é uso da força, se usou a força. A partir daí, cidadão imobilizado, incapacitado, um tapa que se dê, um empurrão, aí já é abuso, já é violência policial... Agora, cidadão na parede, aí já começa a perguntar, tocar em órgãos genitais, o chute na canela para que ele abra as pernas. Isso é violência policial, né? (...) No limite, é cumprir o dever dele, da obrigação profissional dele e sem passar pro outro lado, que é o lado do criminoso. Porque a agressão, por menor que ela seja, é o limite de policiamento, para mim.

(...) A violência, como o nome já diz, é justamente quando ocorre o excesso da força bruta, o que atua de má-fé no intuito de estabelecer ordem, mas que como ela ocorre em excesso ou desvio da força legal, e extrapola os limites, e acaba trazendo e violando os direitos individuais ou prejudicando um bem ou serviço.

(...) Existe uma diferença conceitual, uma diferença dogmática e uma diferença prática. O nosso grande problema é com relação a traduzir os nossos conceitos teóricos em atividades práticas.

Percebe-se nos depoimentos um misto de afirmações calcadas no bom senso e de busca de definições extraídas de situações concretas - através de exemplos e de raciocínios circulares do tipo "até onde a lei assegura é uso da força", configurando a tautologia que algumas vezes preside a 
argumentação. É possível perceber que, na maioria das situações do diaa-dia, cabe ao policial decidir o quanto de força física ele vai utilizar, antes ou depois da imobilização, com ou sem testemunhas, em situação de risco ou não. O mais longe que vão os informantes nesta direção é a referência à legislação federal, a qual necessariamente tem que ser referência para qualquer cidadão, mesmo quando se insiste na questão da legalidade como um divisor de águas entre violência policial e uso da força legítima; a afirmação não se faz acompanhar da referência a um ordenamento específico, direcionado ao tema, produzido pela corporação militar ou civil.

No tocante ao uso da força e de como esta se distingue de violência, chama particularmente a atenção, em Ottawa, a referência explícita aos códigos: o Código Penal, em primeiro lugar - até aí, nada de distinto do que ocorre no DF - mas também a referência ao PSA e aos procedimentos de rotina, que incluem a justificação, através de relatório escrito, detaIhando o porquê de tal ou qual intervenção realizada na atuação prática, conforme apresentado nos depoimentos a seguir:

(...) Sobre o uso da força, de fato nós temos aqui em Ontário um modelo, elaborado pelo Ministério da Justiça, que dá ao policial algumas possibilidades legais de como efetuar uma prisão quando isto envolve interações com outras pessoas (...), obviamente, a presença de um policial uniformizado que pode ser um detrator (...) a qualquer momento durante este processo o policial pode mudar ou manter sua posição de força, ou até mesmo desistir desta posição. Se ele puder justificar o uso da força está tudo bem. Mas, se ele não puder justificar, nós teremos que recorrer ao nosso Police Service Act [código de deontologia] mesmo se o suspeito tiver uma conduta ilegal ou criminosa ${ }^{2}$.

2 Esta e as outras falas dos policiais canadenses foram traduzidas pelos autores. 
(...) A diferença é que nós temos uma seção específica do Código Criminal e do Police Service Act [código de deontologia] que diz que somos autorizados a usar [a força] se for justificada e necessária e não houver outros meios disponíveis de evitá-la. Então nós podemos usar tanto quanto necessário para nos preservar, proteger a vida e aplicar a lei. Nestas seções também evita-se o excesso de força. Se você se excede no uso da força você será responsabilizado por isto e, então, você terá que ser capaz de justificar sua forma de ação.

Além dos problemas para definir o que é violência policial, há também a dificuldade de controlar e monitorar a atividade policial. O enorme poder discricionário de que gozam as polícias está no centro da questão (Walker, 1993; Bandeira e Costa, 2003). Possivelmente, dentre os agentes estatais, os policiais estão entre aqueles que possuem maior liberdade para exercer suas funções, tanto em termos do exercício da autoridade quanto em relação aos controles a que estão submetidos.

Nesse sentido, podemos descrever a atividade policial como um sistema de peritos, ou seja, como "sistemas de excelência técnica ou competência profissional que organizam grandes áreas dos ambientes material e social em que vivemos hoje" (Giddens, 1991, p. 35). Conhecemos muito pouco dos códigos e procedimentos adotados pelos policiais para o exercício da autoridade que lhes foi delegada. Na maioria dos casos, torna-se difícil para um leigo avaliar se a conduta policial foi adequada ou não. Assim, o controle da atividade policial, para ter eficácia, deve levar em conta os códigos de deontologia e a normas de conduta, uma vez que estas representam a experiência acumulada pelos policiais.

Os problemas de definição do que vem a ser violência policial e as dificuldades de monitoramento das práticas cotidianas da polícia tornam pouco eficiente o funcionamento de três dos principais mecanismos de controle da atividade policial existentes: a legislação, o controle externo e a justiça. Skolnick e Fyfe (1993) sustentam que, na prática, as mudanças 
na legislação penal e processual penal só têm efeitos concretos sobre a conduta policial quando os departamentos de polícia decidem reformular suas normas internas de conduta. Bayley $(1991,1994)$ argumenta que as dificuldades de monitoramento do policiamento são o principal obstáculo ao funcionamento efetivo dos órgãos de controle externos das polícias. Com relação à justiça, alguns autores têm apontado suas deficiências para limitar e controlar o uso da força legal (Cheh, 1996; Chevigny, 1995; Cano, 1997; Costa, 2003). Neste caso, o problema repousa na dificuldade de investigar adequadamente e definir, a partir de uma perspectiva externa, o que é violência policial.

Em função destes problemas, algumas polícias optaram por criar códigos de deontologia e normas administrativas para controlar a atividade policial. Um dos primeiros autores a analisar o funcionamento destes códigos e normas, Kenneth Davis (1971) argumentava que algum tipo de discricionariedade nas atividades do sistema de justiça criminal é inevitável. Para ele, o problema não residia na existência da discricionariedade, mas sim na falta de controle sobre ela. Uma vez limitada e estruturada, a discricionariedade poderia passar a ser algo positivo relacionado ao exercício da profissão de policial. Finalmente, Davis sustentava que a melhor forma de lidar com a discricionariedade seria a criação de códigos de deontologia e normas administrativas destinadas a regular o exercício da atividade policial. Passados quase quarenta anos do lançamento do seu livro, suas conclusões, de forma geral, continuam válidas e bastante influentes.

Inquiridos sobre como lidar com a discricionariedade, os policiais de Ottawa, assim como os entrevistados do Distrito Federal, têm alguma dificuldade em se posicionar claramente a respeito; apresentam quase invariavelmente uma resposta defensiva, como se estivesse subentendido que falar em discricionariedade é mencionar um defeito, uma lacuna, uma arbitrariedade em sua forma de atuar, que merece recriminação. Em 
outras palavras, é como se os entrevistados se defendessem por se sentir (ou antes de se sentir) acusados de algum deslize.

(...)Bom, a primeira coisa pra gente tomar uma decisão rápida e trabalhar na rua tranqüilamente é justamente isso que a gente tá tentando fazer aqui na academia. É investir na formação do policial.

(...)Porque, na verdade, não há a delimitação do que fazer. A gente não tem uma manual de... talvez não seja nem possível também delimitar tudo assim, porque o serviço da polícia é mais serviços gerais. Assim... a gente.... né?... costuma dizer que é pra servir, pra atender, mas servir abrange tudo. Então, assim como a gente tem essa liberdade, eu acredito que prá lidar com essa falta de normatização, digamos assim, só o bom senso adquirido no curso de formação.

No caso de Ottawa, o que parece sobressair dos depoimentos é o fato de que discricionariedade é coisa para assuntos menores, transgressões no trânsito, ou coisas do gênero. Nas demais situações, o policial não deve usar de (ou, uma nuance interessante, não precisa de) discricionariedade; ele aplica a lei. O que, em última instância, não deixa de ser uma forma velada de negar a discricionariedade, de não responsabilizá-la pela prática policial em momentos cruciais de sua atuação:

(...) Na minha visão sobre discricionariedade, ela deveria ser aplicada apenas nas violações de trânsito. Eu acho que em alguns casos você pode dar uma chance para alguém, dependendo as circunstâncias. Mas quando se trata de atos criminosos não deveria haver discricionariedade. O policial tem que fazer o seu trabalho. Se houver um crime, você analisa os fatos; você decide seirá ou não proceder a uma prisão com base nas informações que você dispõe. Em alguns casos você tem a informação mas não pode prender. Isto não é discricionariedade de fato, [uma vez] que está estabelecido na lei. Então a discricionariedade que nós permitimos ao policial daqui é sobre violações de tráfico. Nos casos de crime eles têm que seguir os procedimentos, escrever os relatórios. E deve haver determinações sobre se você tem ou não discricionariedade sobre os seus deveres. 
(...) Bem, depende das normas. Eu diria que há discricionariedade se você está lidando com contravenções, como as infrações de trânsito. Mas qualquer coisa mais séria, você tem que fazer seu trabalho. Colocar no relatório, você sabe (...)

(...) A discricionariedade nos empodera, mas também temos que ter bom senso (...) você usa a discricionariedade em situações, que na minha opinião pessoal, não são assuntos sérios, quando você quer advertir alguém, como numa infração de trânsito.

Em Ottawa transparece a existência de um procedimento que parece acompanhar e guiar a rotina policial: a necessidade de entrega de relatórios escritos, detalhando e justificando ações da atividade policial. As situações em que os policiais admitem que não pode haver discricionariedade são aquelas que são objeto de regulamentação clara, tais como algumas previstas nos guidelines; violência doméstica, violência contra criança ou, ainda, como e quando perseguir um suspeito ou um carro, o que implica o uso de velocidade pelo policial. Em suma, quando o policial conhece a lei - é o que eles subentendem em seus depoimentos -, discricionariedade não chega a ser problema; atualmente, afirmam alguns dos entrevistados, a legislação é muito clara, seja para uso da força, seja para atuação em caso de violência doméstica, de violência contra a criança, de perseguição de suspeitos ou criminosos, entre outros temas contemplados nos guidelines.

A criação de normas administrativas permite um equilíbrio entre o que prescreve a legislação e o que realmente a polícia faz no seu dia-adia. Embora a legislação possa orientar algumas atividades da polícia, principalmente aquelas relacionadas ao controle da criminalidade, na prática há inúmeras questões não prescritas na lei que têm enorme repercussão no exercício da atividade policial. Pode-se dizer que a lei prescreve o que deve ser feito, mas não diz quase nada sobre quando e como fazer. 
O desafio atual das polícias que já implantaram códigos de deontologia e normas administrativas para regular algumas das atividades dos seus membros é evitar que estas normas tornem-se meras formalidades. Ou seja, evitar que a discricionariedade migre da aplicação da lei para o cumprimento das normas administrativas. Em muitos casos, é exatamente isso que acontece, uma vez que a simples existência de uma norma não garante o seu cumprimento.

Uma norma é uma diretriz formal destinada a orientar condutas individuais. Para tal, ela precisa ser coercitiva e específica. Coercitiva porque necessita obrigar os membros da instituição a se adequarem às condutas prescritas. Específica, uma vez que as normas genéricas possibilitam diferentes interpretações sobre o seu conteúdo, deixando de uniformizar as condutas individuais.

Uma vez que são internas à instituição, somente a adesão dos membros da polícia, principalmente dos mais graduados, à idéia de que as normas administrativas são importantes instrumentos de gestão das instituições policiais, poderá fazer com que elas não se tornem meras formalidades. Do contrário, o peso das práticas informais e a relutância dos policiais mais graduados poderão torná-las sem efeito. Para que códigos e normas limitem e estruturem de fato a discricionariedade policial, algumas polícias adequaram seus sistemas de treinamento e de avaliação de condutas individuais.

\section{Comparando os Códigos de Deontologia}

Para entender melhor a natureza e o significado dos códigos de deontologia, decidimos comparar os códigos utilizados em duas diferentes instituições policiais: a Polícia Militar do Distrito Federal (PMDF) e o Ottawa Police Service (OPS). Foram considerados apenas aqueles estatutos que tem força de lei, uma vez que o caráter coercitivo é característica essencial dos códigos de deontologia. Desta forma, foram analisados: a) o 
Estatuto da Polícia Militar do Distrito Federal (PMDF); b) o Código de Ética Profissional (PMDF); c) o Police Services Act (OPS) e d) o Adequacy and Effectivenes of Police Services (OPS).

$\mathrm{Na}$ análise de cada um destes documentos, consideram-se os artigos ou seções como unidades de análise. Embora, frequentemente os artigos ou seções possuíssem inúmeros incisos ou alíneas, estas foram consideradas no seu conjunto e não separadamente. Cada unidade de análise foi examinada separadamente por pelo menos dois pesquisadores. Ao final do processo, compararam-se todas as análises realizadas. Os itens que apresentaram divergências foram revistos a fim de dirimir os conflitos de interpretação. A idéia geral deste tipo de procedimento de pesquisa foi construir coletivamente uma interpretação sobre os documentos analisados.

Foram utilizadas as seguintes categorias para analisar todos os documentos: a) definição de termos, considerações iniciais e considerações finais; b) organização interna; c) deveres, direitos e proibições; d) procedimentos profissionais e e) outros.

Foram classificados como definição de termos, considerações iniciais ou finais aqueles artigos que traziam conceitos gerais e definições que serviriam de base para a interpretação dos demais artigos. Por exemplo, tanto nos documentos brasileiros quanto nos canadenses foram encontrados artigos definindo ou diferenciando policiais e funcionários civis. Também foram classificados nesta categoria os conteúdos que tratam da competência e da abrangência de cada documento.

Muitos conteúdos foram classificados como organização interna. De forma geral, eles tratam da organização e da distribuição de competências dos diferentes órgãos e seções de cada organização policial. Alguns artigos descrevem a estrutura (composição e competência) de determinada unidade policial. Outros tratam das relações entre estas diferentes unidades.

A categoria deveres, direitos e obrigações foi empregada para classificar os itens que descrevem, de modo geral, os direitos e prerrogativas dos policiais. Também foram enquadrados nesta categoria os conteúdos 
que descrevem as especificidades de determinadas funções policiais. Nos documentos brasileiros e canadenses foram encontrados artigos tratando dos direitos trabalhistas dos policiais (férias, remunerações e licenças), também foram encontrados conteúdos que dizem respeito a seus direitos e prerrogativas judiciais. Os itens referentes às obrigações funcionais dos policiais foram classificados desta forma.

Os artigos que tratavam ou descreviam os procedimentos para o exercício da profissão de polícia foram classificados como procedimentos profissionais. Nesta categoria estão desde a previsão para o estabelecimento de procedimentos profissionais até a descrição de procedimentos específicos. Finalmente, foram classificados como "outros" os conteúdos que não puderam ser classificados em nenhuma das categorias anteriores.

Distrito Federal: códigos de deontologia sem normas de conduta

No Brasil, tradicionalmente, as polícias militares estiveram ligadas ao Exército. Em alguns períodos históricos, elas estiveram sobre o controle direto do Ministério do Exército. Esta identidade entre policiais e militares teve profundas conseqüências no desenvolvimento da deontologia policial. Muitas polícias militares adotaram (ou adotam) o Estatuto dos Militares, elaborado pelas Forças Armadas, bem como, utilizam o Regulamento Disciplinar do Exército e inúmeros manuais empregados no treinamento dos militares do Exército. A partir da última década, esta situação começou a mudar em alguns estados brasileiros. Seguindo a tendência mundial, algumas polícias militares brasileiras criaram seus próprios códigos de deontologia e outras iniciaram estudos para a elaboração de manuais de conduta ${ }^{3}$. É o caso da Polícia Militar do Distrito Federal (PMDF), que estabeleceu o Estatuto da

3 Dentre elas destacam-se as iniciativas verificadas em São Paulo, Minas Gerais, Goiás, Mato Grosso do Sul e Pernambuco para a criação de Códigos de Deontologia e o estabelecimento de Procedimentos Operacionais Padrão (POP's). 
Polícia Militar do Distrito Federal, prescrevendo as responsabilidades, os direitos e os deveres de todos os membros desta instituição policial. Em 1997, foi criado também o Código de Ética Policial. Neste código estão descritos os princípios e valores que deverão orientar a atividade de policiamento e as condutas dos policiais. Os conteúdos do Estatuto e do Código de Ética evidenciam seu caráter formal, geral e pouco restritivo quanto às orientações que disponibilizam para a conduta policial.

Dos 145 artigos do Estatuto, os conteúdos relativos a procedimentos profissionais que regulamentam a relação com a sociedade não estão contemplados. As prescrições, de caráter normativo, concentram-se fundamentalmente em organização interna da polícia, definições gerais, e direitos e obrigações dos policiais militares. Os artigos que tratam dos aspectos organizacionais da instituição são os mais numerosos. Estes estão, sobretudo, ligados à hierarquia e à disciplina e podem conter instruções sobre a relação do policial com seus pares e superiores.

A seguir, vêm os artigos com conteúdos administrativos e de considerações iniciais ou finais. Os deveres, os direitos e as proibições, mais diretamente ligados à postura, e que, em tese, poderiam trazer prescrições de natureza moral ou profissional, ocupam o terceiro lugar na frequência de artigos do estatuto. Em sua análise, percebeu-se que os princípios norteadores da atividade profissional ocupam aí posição secundária, quando comparados a deveres e obrigações em formulações de natureza mais geral. 
Tabela 1. Estatuto dos Policiais Militares da Polícia Militar do Distrito Federal

\begin{tabular}{ccc}
\hline Conteúdo dos artigos & Frequência & Frequencia Relativa (\%) \\
\hline $\begin{array}{c}\text { Definição de termos, } \\
\text { considerações iniciais e finais }\end{array}$ & 38 & 26,21 \\
Organização Interna & 72 & 49,66 \\
Deveres, direitos, proibições & 31 & 21,38 \\
Procedimentos profissionais & 0 & 0 \\
Outros & 4 & 2,76 \\
\hline Total & $\mathbf{1 4 5}$ & $\mathbf{1 0 0}$ \\
\hline
\end{tabular}

Fonte: Estatuto da Polícia Militar do Distrito Federal (Lei 7454/1986).

A análise da frequência dos assuntos tratados no Estatuto apenas nos dá uma pista sobre seu caráter geral e sua finalidade. O Estatuto é um documento centrado nos deveres ligados à disciplina e à hierarquia, estando fortemente impregnado da cultura hierárquica do exército. Aliás, hierarquia e disciplina formam o pano de fundo que organiza o conjunto do documento. O grau de generalidade de sua formulação torna bastante difícil, senão impossível, traduzi-los em subsídios para a formulação de normas de conduta, de procedimentos específicos, profissionais. Seus deveres são, na sua maioria, os deveres do cidadão.

Isto não seria um problema se, no domínio dos procedimentos profissionais, o legislador detalhasse melhor as especificidades que daí poderiam decorrer para a atividade policial, mas não é o que acontece. Da mesma forma, a tradução destes princípios norteadores em normas ou manuais práticos, orientadores de conduta, seria uma maneira de compensar o caráter geral dos deveres policiais, mas aí também a lacuna é enorme.

Situação semelhante pode ser constatada pela leitura dos 09 artigos que compõem o Código de Ética, cuja frequência dos conteúdos está resumida na tabela e gráfico número $02{ }^{4}$ Todo o conteúdo do texto é relativo a prescrições morais, pertinentes ao cidadão mais do que ao profissional.

4 Portaria PMDF nr. 142 de 15/07/1997. 
Tabela 2. Código de Conduta Ética Profissional - PMDF

\begin{tabular}{cc}
\hline Conteúdo dos artigos & Frequência \\
\hline Definição de termos, considerações & 1 \\
iniciais e finais & \\
Organização Interna & 0 \\
Deveres, direitos, proibições & 8 \\
Procedimentos profissionais & 0 \\
Outros & 0 \\
\hline Total & $\mathbf{9}$ \\
\hline
\end{tabular}

Fonte: Código de Conduta Ética Profissional da Polícia Militar do DF

Na apresentação deste código, seu autor aponta a adequação do mesmo às diretrizes da Assembléia Geral das Nações Unidas, que, a 17 de dezembro de 1979, aprovou um Código de Conduta para funcionários encarregados de fazer cumprir a lei. ${ }^{5}$ As entrevistas efetuadas indicam, porém, que nem todos na corporação estão conscientes desta articulação. Além disso, chama também a atenção o fato de o código se definir como um código de ética profissional. Com relação a este aspecto, é interessante observar que, apesar do título remeter à questão da profissão, no capítulo que trata dos deveres, fala-se em atividade policial, em serviço, e não em profissão policial. Além de preferir o termo atividade policial, o Código, quando faz menção à profissão, o faz de modo absolutamente vago, como indicam os exemplos abaixo:

Art. 2 o, Inc. II - Exercer a atividade policial com zelo, diligência, honestidade e respeito à pessoa humana e aos direitos humanos.

Art. 6으, Inc. III - Praticar o profissionalismo e desenvolver permanentemente o espírito de corpo.

Art. 6 , Inc. IV - Empregar todas as energias em benefício do serviço.

5 Em negrito no original. 
Nenhum dos artigos do Código de Conduta Ética Profissional trata de modo específico da relação do policial com a sociedade, o que chama a atenção, posto que se trata de um código de deontologia policial. O artigo 03, que trata do desempenho das funções, diz ao policial que ele deve:

Art 3 o, Inc. I - se esforçar para atuar oportunamente, sem permitir que seus sentimentos (prejudiciais), animosidade ou amizades influam em suas decisões;

Art 3o, Inc. II - não ceder ante o delito e perseguir incansavelmente os delinquentes, fazendo cumprir a lei com cortesia e de forma apropriada, sem temor nem favoritismo, malícia ou má vontade; sem empregar força ou violência desnecessária, nem aceitar gratificações ou suborno; Art 3으, Inc. III - lutará constantemente para lograr estes objetivos e ideais: de dedicar a Deus, à Pátria e à profissão que houvera escolhido e fazer cumprir a lei com o sacrifício da vida se for necessário, como um dia jurou ante nossa Bandeira Nacional.

Aqui, onde o que é específico da função policial poderia remeter de modo direto à questão de prescrições mais claras e objetivas quanto ao uso da força, permanece o caráter vago. Expressões como atuar oportunamente, cumprir a lei com cortesia, sem empregar força ou violência desnecessária, se dedicar à profissão escolhida precisam ser definidas de forma clara e objetiva. Entretanto, isso não é feito nem no Código e tampouco nos manuais em uso na PMDF. As possibilidades de avançar subsídios para, num manual específico, estruturar o espaço da discricionariedade e seu uso, são assim desperdiçadas. Dentre os termos selecionados para figurarem em letras maiúsculas não está contemplado o que se refere à profissão.

Os princípios doutrinários, onde, a rigor, se inscrevem os valores e a filosofia da atuação profissional, são apresentados no artigo 7ํㅡ, constituído por 23 parágrafos, que mantêm o mesmo nível de generalidade já registrado anteriormente, indo desde a observância da boa educação, da camaradagem, do espírito de cooperação, até as exortações que incidem sobre a 
vida privada do cidadão policial militar. Todos esses conteúdos são descritos da mesma forma daqueles que tratam, por exemplo, da manutenção da ordem e da segurança da comunidade. Como é definida a segurança da comunidade? O que é prevenção da ordem pública? O que significa zelar pela sua competência exclusiva, na prevenção e manutenção da ordem pública? Não há nenhum detalhamento sobre isto.

Da mesma forma, no art $8^{\circ}$, que trata do valor policial, figuram conceitos como patriotismo, civismo, culto às tradições históricas da corporação, fé na missão elevada da polícia, amor à profissão e o entusiasmo para exercê-la, aprimoramento técnico profissional, espírito de corpo e o orgulho pela corporação, dedicação na defesa da sociedade. Mistura-se, de modo abrangente e vago, prescrições de teor e de consequências bastante diferenciadas. O que seriam esses valores e como traduzi-los para a conduta prática? Como eles poderiam ser cobrados num processo de avaliação profissional?

O artigo 9o relaciona os princípios consagrados de ética profissional. $\mathrm{Na}$ forma de definir a responsabilidade no trabalho, explicita-se a proteção e o socorro à comunidade, que se concretiza, no entanto, pela defesa de suas leis e, mais especificamente, da Constituição Federal. Ou seja, mais uma vez, a relação com a comunidade é contornada e apresentada através da proteção às leis, distante de algo mais direcionado à natureza da relação polícia-sociedade.

Em resumo, são princípios vagos o suficiente para que não se acuse o código de não contemplá-los, concedendo um maior espaço à discricionariedade. Como usar esta discricionariedade de forma adequada? Essa é a questão que os códigos, pelo seu grau de indeterminação, não ajudam a dirimir. Em si, a discricionariedade, presente na atuação policial, nada tem de bom ou de ruim. Depende de como lidar com ela, como defini-la, como estruturá-la.

Tanto no Estatuto quanto no Código, há uma enorme lacuna no tocante a procedimentos profissionais. Uma das formas de lidar com estas 
lacunas é o estabelecimento de manuais de conduta policial. No caso da PMDF, os manuais existentes são por demais genéricos. De forma geral, eles não trazem orientações claras de como proceder em situações específicas, especialmente naquelas relacionadas ao uso da força e ao trato com os cidadãos.

Dos manuais existentes na $P M D F$, boa parte refere-se às atividades especiais de policiamento, tais como, controle de tumultos, policiamento de trânsito e policiamento a cavalo. Embora sejam importantes, estas atividades respondem por menos de $20 \%$ do efetivo empregado no policiamento do Distrito Federal. O policiamento ostensivo, principal atividade da polícia militar, não conta com um manual específico, que apresente orientações claras aos policiais de como proceder.

O Manual Básico de Policiamento, utilizado no treinamento básico dos policiais, não contém normas de condutas específicas para os policiais. De forma geral, nele estão descritos os principais tipos de policiamento utilizados no Distrito Federal: policiamento ostensivo, policiamento de trânsito e rodoviário, policiamento de guardas, policiamento escolar e policiamento feminino. Traz também uma seção sobre noções de direito.

No que diz respeito ao uso da força, não diz como os policiais deveriam proceder. Na seção que trata de armamento e tiro, verifica-se uma série de conteúdos técnicos sobre os tipos de armas, seu histórico e especificidades. Não há nenhuma prescrição sobre quando e como usar o armamento. $\mathrm{O}$ mesmo pode ser dito quanto à abordagem policial, à conduta com presos, a perseguições motorizadas e à violência doméstica.

Nada é dito sobre estes temas. Embora existam manuais, concretamente eles não fazem parte do dia-a-dia da prática policial, orientando condutas. Não funcionam como a 'bíblia' do policial militar. Dito de outro modo, não se incorporam como valores, como padrão de comportamento, ou ainda como novas posturas profissionais. Enquanto não se puder 
pensar a profissão e o conceito de profissionalismo a partir de valores, saberes e práticas (perspectiva foucaultiana das relações intrínsecas entre "saber e poder") que orientem a conduta policial, sobretudo no momento em que a ação rápida exige os condicionamentos necessários, estaremos no domínio do senso comum e do bom senso. Situação esta que remete ao arbítrio do ator a decisão sobre a melhor forma de agir, no momento do exercício da profissão.

Ontário: códigos de deontologia com normas de conduta

No Canadá, diversas forças policiais passaram a contar com códigos de deontologia, a partir da década de 1940. Estes códigos não necessariamente se restringiram a uma instituição policial específica. O caráter federativo do seu sistema político e o fato de algumas das principais organizações policiais estarem sob controle dos municípios são aspectos importantes do sistema policial canadense. Em função disso, algumas províncias estabeleceram autoridades responsáveis pela coordenação e controle dos serviços de polícia: o Solicitor General. ${ }^{6}$ Para tal, estas autoridades se valem dos códigos de deontologia e de regulamentações administrativas sobre as condutas policiais.

É o caso da província de Ontário, onde todos os serviços policiais ali existentes (municipais e provinciais) devem seguir o que estabelece o Police Services Act (PSA), criado em 1990. Nele, além dos princípios norteadores das atividades policiais, também estão previstas as responsabilidades das polícias e dos seus membros. Além disso, o código de deontologia canadense regula as relações de trabalho dentro das organizações policiais, bem como as formas e procedimentos para apresentar queixas e reclamações sobre a conduta profissional dos policiais.

6 No Brasil, cabe aos secretários de segurança pública exercer boa parte das funções políticas e administrativas do Solicitor General. 
O Police Services Act foi criado para substituir o Police Act de 1946, a fim de tratar mais adequadamente as mudanças sociais, políticas e econômicas ocorridas nas últimas quatro décadas. O PSA buscou fortalecer as relações entre a polícia e a comunidade, sendo bastante enfático sobre a necessidade de parceria com a comunidade. Dentre as várias mudanças introduzidas no novo código de deontologia, destaca-se a ênfase na natureza dos serviços prestados à comunidade e na necessidade de aumentar o controle da atividade policial.

O novo código estabelece que os chefes das polícias municipais devem implantar a filosofia de policiamento comunitário, voltada para a solução de problemas (community-oriented policing). De forma geral, o PSA confirma a tendência, verificada desde a década de 80, de enfatizar a necessidade de aproximar polícia e comunidade. Não por acaso, a expressão 'serviço' foi incorporada ao título do novo código canadense.

Para melhorar o controle sobre as atividades policiais, dois novos mecanismos foram criados pelo PSA. O artigo 113 estabelece que todos os serviços de polícia na província de Ontário deveriam criar uma unidade especial de investigações - Special Investigations Unit (SIU). Cabe a esta nova unidade conduzir investigações sobre os desvios de conduta que porventura forem cometidos por policiais. Esta unidade especial deverá reportar-se diretamente ao Ministério Público de Ontário.

Além disso, o Police Services Act passou a uniformizar e detalhar mais os procedimentos a serem seguidos para lidar com as queixas e reclamações dos cidadãos a respeitos dos serviços prestados pela polícia. A parte IV do PSA estabelece os procedimentos a serem seguidos por todos os serviços de polícia. Também trata das funções e deveres dos chefes de polícia, bem como dos direitos e deveres dos policiais acusados.

Outra novidade do código canadense foi a criação de um órgão de controle externo para supervisionar as atividades de todos os membros 
dos serviços de polícia de Ontário. A seção 21 criou a Ontario Civilian Commission on Police Services (OCCPS). A comissão serve como instância quase judicial, destinada a servir como corte de apelação dos processos disciplinares conduzidos por cada serviço de polícia. Ela pode conduzir suas próprias investigações, requerer investigações especiais dos serviços de polícia, bem como rever as decisões dos chefes de cada departamento de polícia.

Da mesma forma que o código de conduta ética do DF, o Police Services Act é carente de conteúdos voltados a procedimentos, como indicam a tabela e o gráfico de número 03, e o gráfico comparativo entre eles. Os conteúdos relacionados a questões organizacionais são os mais frequentes, seguidos daqueles que tratam dos direitos, deveres e obrigações dos policiais. Os dados agrupados permitem melhor visualização do que se está afirmando.

Tabela 3. Police Services Act - Conteúdo dos Artigos

\begin{tabular}{ccc}
\hline Conteúdo dos artigos & Frequência & Frequencia Relativa (\%) \\
\hline $\begin{array}{c}\text { Definição de termos, } \\
\text { considerações iniciais e finais }\end{array}$ & 5 & 4,85 \\
Organização Interna & 83 & 80,58 \\
Deveres, direitos, proibições & 14 & 13,59 \\
Procedimentos profissionais & 0 & 0 \\
Outros & 1 & 0,97 \\
\hline Total & $\mathbf{1 0 3}$ & $\mathbf{1 0 0}$ \\
\hline
\end{tabular}

Fonte: Police Services Act. 
Gráfico 1

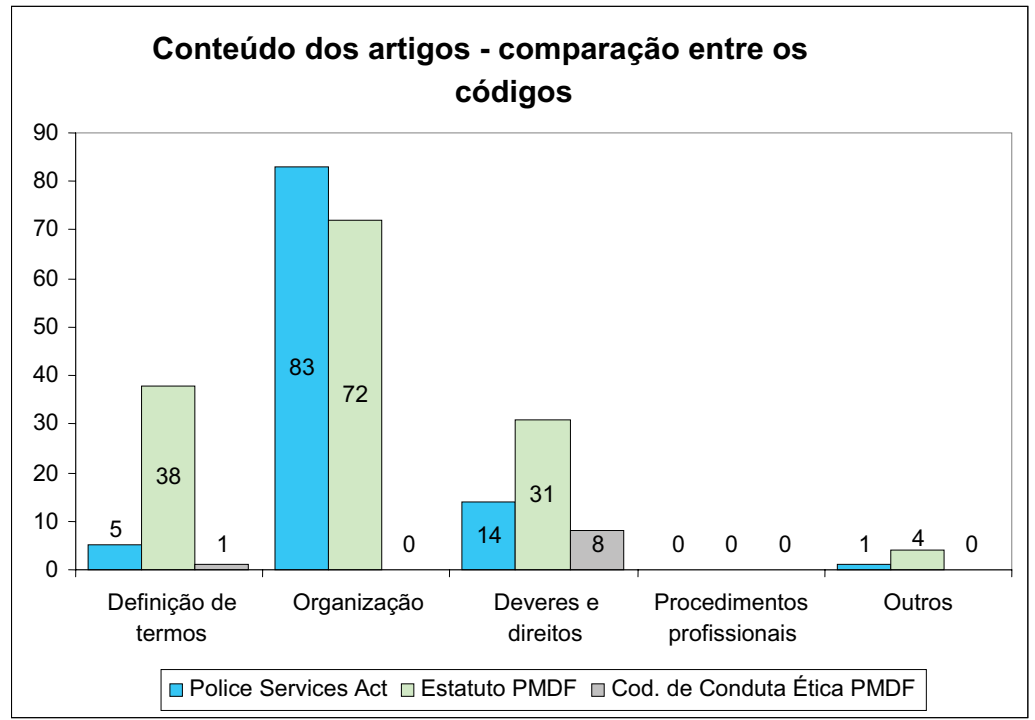

Fonte: Police Services Act.

Gráfico 2

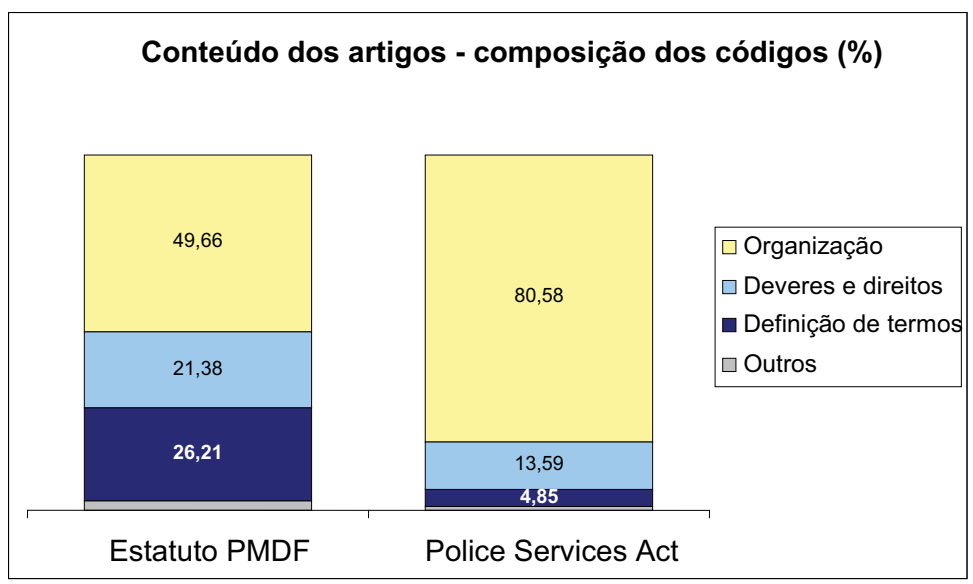


Também, a exemplo do estatuto brasileiro, o código canadense não estabelece de forma clara como os policiais deveriam exercer suas funções. Apenas fornece os princípios que deveriam nortear o trabalho dos policiais. O artigo 42 do Police Services Act estabelece os deveres dos policiais:

Art 42 (a) - preservar a Paz;

Art 42 (b) - prevenir crimes e outras ofensas e prover assistência e encorajamento para que outras pessoas o façam;

Art 42 (c) - assistir as vítimas de crimes;

Art 42 (d) - prender criminosos e outras pessoas que possam legalmente ser postas em custódia;

Art 42 (f) - executar mandatos que possam ser executados por policiais e desempenhar suas obrigações relativas;

Art 42 (g) - desempenhar as obrigações legais que o chefe de polícia lhes destinar.

Estas obrigações são por demais vagas para orientar as condutas policiais. Nada dizem sobre como prevenir crimes, assistir vítimas, prender criminosos, executar mandatos ou desempenhar obrigações legais? De forma alguma, o Police Services Act se presta a disciplinar as atividades cotidianas dos policiais. É necessário que se estabeleçam normas de condutas específicas sobre estes princípios e diretrizes.

Em 1999, o Solicitor General de Ontário estabeleceu o Adequacy and Effectiveness of Police Services. ${ }^{7}$ Esta regulação visava cobrir as lacunas deixadas pelo PSA, sem,contudo, quebrar as autonomias municipais de organizar e controlar seus próprios serviços de polícia. De fato, a análise dos seus conteúdos evidencia uma preocupação muito maior com o estabelecimento de procedimentos profissionais e normas de condutas policiais, como mostra a tabela 4.

7 Regulação provincial 3/1999. 
Tabela 4. Adequacy and Effectiveness of Police Services - conteúdo dos artigos

\begin{tabular}{ccc}
\hline Conteúdo dos artigos & Frequência & Frequencia Relativa (\%) \\
\hline $\begin{array}{c}\text { Definição de termos, } \\
\text { considerações iniciais e finais }\end{array}$ & 3 & 8,11 \\
Organização Interna & 15 & 40,54 \\
Deveres, direitos, proibições & 0 & 0 \\
Procedimentos profissionais & 19 & 51,35 \\
Outros & 0 & 0 \\
\hline Total & $\mathbf{3 7}$ & $\mathbf{1 0 0}$ \\
\hline
\end{tabular}

Fonte: Ontario Regulation 3/99.

Uma vez que compete às autoridades municipais organizar e controlar seus próprios serviços de polícia, o Adequacy and Effectiveness estabelece de forma clara e obrigatória (mandatory) que os chefes de polícia implementem normas e procedimentos profissionais sobre determinados assuntos. Vejamos alguns exemplos do que diz a regulação:

Art. 12 - Todo chefe de polícia deverá desenvolver e implementar procedimentos e processos para conduzir investigações criminais sobre:

(a) abuso físico e sexual de crianças;

(d) violência doméstica;

(i) homicídios e tentativas de homicídios;

(I) pessoas perdidas.

Art. 13 - Todo chefe de polícia deverá estabelecer processos e procedimentos a respeito de:

(f) proteção e segurança de testemunhas;

(h) revista de pessoas;

(j) prisões;

(I) controle e cuidado de prisioneiros.

Ou seja, a autoridade de segurança pública da província de Ontário exige que as policiais municipais implantem normas de condutas sobre uma serie de assuntos. Entretanto, caberá aos municípios determinar o conteúdo destes procedimentos. Para se ter uma idéia, o Ottawa Police 
Service conta com mais de uma centena de normas de condutas e procedimentos policiais (policies e guidelines). Tais normas e procedimentos tratam dos mais variados assuntos, como uso da força policial, violência doméstica, controle de tráfico, perseguições motorizadas e proteção à testemunha. Tradicionalmente, os serviços de polícia de Ontário adotam as mesmas normas de condutas e procedimentos profissionais. Esta medida facilita o treinamento básico dos policiais, cuja primeira parte é unificada, como veremos na próxima seção.

\section{Normas de Conduta, Treinamento e Avaliação}

A existência de um código de deontologia não assegura que seus valores profissionais sejam compartilhados por todos, irrigando cotidianamente as ações da polícia. A eficácia dos códigos de deontologia é proporcional ao grau de adesão aos seus valores pelos agentes policiais. Para que isto aconteça, algumas polícias reestruturaram seu aparato administrativo de controle interno para fazer valer estes princípios na prática policial cotidiana. Enquanto o código de deontologia busca relacionar os valores e ideais de uma determinada ordem política e social aos ditames da profissão policial, o aparato administrativo procura transformar estes ditames à prática cotidiana.

Diferente de um sistema voltado exclusivamente para a punição dos desvios de conduta individual, este aparato administrativo visa, fundamentalmente, prevenir situações e riscos para a polícia e os cidadãos. Para tanto, procura reduzir os "espaços discricionários" de que gozam os policiais, bem como premiar aqueles profissionais que conduzam suas ações de acordo com os princípios indicados no código de deontologia. Portanto, a existência desse aparato administrativo de controle interno não implica no fim da violência policial, mas na redução das situações 
nas quais essa violência pode ocorrer. Basicamente, este aparato policial é composto de três elementos: as normas de conduta, o treinamento e o sistema de supervisão e avaliação.

A seguir, comparamos o sistema de treinamento e avaliação da Polícia Militar do Distrito Federal e do Ottawa Police Service.

\section{Polícia Militar do Distrito Federal}

Existem várias formas de ingresso na Polícia Militar do Distrito Federal. As duas mais frequentes são através da Academia de Polícia Militar de Brasília (APMB) e do Centro de Formação e Aperfeiçoamento de Praças (CFAP). A APMB forma os oficiais em seu curso superior, reconhecido pelo Ministério da Educação. O CFAP forma as praças (soldados, cabos, sargentos e sub-tenentes) da polícia. Observa-se que, a partir da década de 90, houve um esforço da PMDF em ampliar o currículo dos seus cursos de formação, tanto na $A P M B$ quanto no CFAP. ${ }^{8}$

Atualmente, o curso de formação de oficiais tem duração de 03 (três) anos, inclui quatro áreas de disciplinas: ensino acadêmico básico, ensino acadêmico profissional, ensino profissional específico e atividades complementares. Dentre outras, fazem parte do ensino acadêmico básico disciplinas como "ética e deontologia", "psicologia" e "relações públicas e humanas". O ensino acadêmico profissional envolve disciplinas de conteúdo jurídico, além de "criminalística" e "criminologia". O ensino profissional específico trata dos assuntos diretamente relacionados às atividades

8 Os esforços de ampliar o currículo da formação policial, incluindo disciplinas de conteúdos humanistas, não ocorreram apenas no Distrito Federal. Outros estados como Rio Grande do Sul, São Paulo, Minas Gerais, Pernambuco e Pará, por exemplo, também fizeram grandes mudanças nos seus programas de formação de praças e oficiais. Em 2002, o governo federal, através da Secretaria Nacional de Segurança Pública (SENASP) elaborou a Matriz Curricular Nacional. Esta matriz se propõe a ser um referencial nacional para a formação de policiais no Brasil. No currículo comum proposto pela matriz, constam disciplinas como "direitos humanos", "ética e cidadania" e "relações humanas". 
cotidianas da polícia. "Legislação e regulamentos", "policiamento ostensivo", "armamento, munição e tiro" são algumas das disciplinas desta área. Dentre as atividades complementares, constam 120 horas (40 por ano) de prática supervisionada na disciplina "exercício de polícia ostensivo". Para o policiamento específico, no entanto, os manuais existentes são apenas obras de referência, sem força de lei.

A Polícia Militar do Distrito Federal conta com poucas normas de condutas estabelecidas oficialmente e sistematizadas na forma de manuais de instrução. Elas tratam principalmente das atividades de controle de trânsito e sobre a utilização de determinados equipamentos. Pode-se dizer que nenhum material utilizado no treinamento básico dos policiais no Distrito Federal pode ser caracterizado como norma de conduta policial. As duas principais obras utilizadas nas instruções sobre policiamento ostensivo são o Manual de Policiamento Ostensivo e o Manual Básico de Policiamento.

Tais manuais não estabelecem procedimentos a serem adotados nas atividades cotidianas de policiamento que envolvam o uso legal da força ou outros tipos de interações com cidadãos. Trazem extensas descrições sobre o que vem a ser policiamento ostensivo, suas modalidades e especificidades. Deste modo, pouco servem para orientar e limitar o uso da autoridade policial. Assim, os princípios, responsabilidades, direitos e obrigações descritos nos códigos de deontologia tornam-se apenas "boas intenções", pois não se apóiam em outros manuais que permitam a sua operacionalização.

A Corregedoria da Polícia Militar do Distrito Federal (CPMDF) é o órgão encarregado de coordenar e avaliar as sindicâncias e os inquéritos sobre os desvios de conduta profissionais cometidos por policiais. As denúncias de desvio de conduta policial e as reclamações acerca dos serviços prestados pela Polícia Militar do Distrito Federal podem ser feitas de várias formas, dentre elas: nas ouvidorias de polícia, na delegacia de polícia judiciária militar, nas delegacias de polícia civil. Além desses, a 
mídia e o Ministério Público e a Comissão de Direitos Humanos da Câmara Legislativa do DF também são importantes veículos de denúncias e reclamações. As denúncias recebidas por estes órgãos, via de regra são encaminhadas para a CPMDF (Silva, 2008).

Entretanto, não há nenhum órgão específico responsável pela apuração e investigação das denúncias de desvio de conduta policial. Também não há regras claras de como a polícia deverá proceder. Uma vez recebida, a denúncia poderá ser encaminhada ao comandante da unidade dos policiais envolvidos no incidente. Ele poderá, de acordo com o julgamento da gravidade dos fatos denunciados, determinar a abertura de uma sindicância ou a instauração de um inquérito policial. Pode ocorrer também que a denúncia seja investigada pela própria corregedoria que, para isso, conta com uma equipe própria.

Em qualquer dos casos, os procedimentos legais adequados para tratar as denúncias são as sindicâncias e os inquéritos policiais. ${ }^{9}$ Uma vez concluídos, tanto as sindicâncias quanto os inquéritos deverão ser encaminhados à corregedoria para a correição dos procedimentos. Para isso, a corregedoria conta com duas seções: a Seção de Procedimentos Judiciais (SPJ) e a Seção de Procedimentos Administrativos (SPA). Compete a SPJ receber, realizar a correição e encaminhar ao Ministério Público todos os inquéritos policiais instaurados na PMDF. Cabe também a SPA, receber, revisar e arquivar todas as sindicâncias e memorandos acusatórios realizados na instituição.

A revisão e a correição das sindicâncias e dos inquéritos tratam dos aspectos jurídico-formais dos processos e das conclusões das investigações. As conclusões das investigações devem estar fundamentadas pela legislação

9 A sindicância é um procedimento interno da polícia, de rito e complexidade mais simples. Já os inquéritos policiais são mais complexos e devem obrigatoriamente ser encaminhados ao Ministério Público que poderá: a) arquivá-lo; b) arquivá-lo com indicação de transgressão disciplinar; c) denunciar os indiciados pelos crimes cometidos ou d) declinar da competência para tratar do assunto. 
existente, bem como pelas normas administrativas em vigor. De modo geral, são três os principais instrumentos utilizados pela corregedoria para avaliar as condutas dos policiais, além do código penal: o Regulamento Disciplinar da Polícia Militar; o Estatuto da PMDF e o Código de Ética Profissional.

A ausência de normas de conduta nas polícias brasileiras tem acarretado problemas também na supervisão e na avaliação dos policiais. Como vimos anteriormente, nem o Estatuto da PMDF nem o Código de Ética Profissional estabelecem orientações claras para as condutas dos policiais. Tampouco o Regimento Disciplinar da Polícia Militar pode ser considerado instrumento adequado para impor os valores profissionais da polícia.

\section{Ottawa Police Service}

De modo semelhante a alguns países europeus, no Canadá, a formação policial é bastante integrada ao sistema educacional daquele país. Os candidatos à carreira policial devem obrigatoriamente ter completado com êxito pelo menos quatro anos do ensino secundário ou equivalente. Muitos dos policiais do Ottawa Police Service freqüentaram algum dos cursos técnico-profissionais oferecidos pelos colleges canadenses.

Na província de Ontário, processo de seleção e parte do treinamento dos policiais é responsabilidade da Ontario Association of Chiefs of Police. A OACP é a associação profissional autorizada a emitir o certificado necessário para contratação de policiais. Para receber o certificado, os candidatos deverão completar as quatro fases do processo de seleção.

Após ser aprovado nas primeiras etapas do processo de seleção, compostas de teste escrito, entrevistas e investigação sobre seu passado, o candidato é enviado ao Ontario Police College. Lá ele irá freqüentar, durante 12 semanas, o Treinamento Policial Básico (Basic Constable Training). Neste período, os candidatos frequentam as seguintes disciplinas: anti-racismo, policiamento comunitário, táticas defensivas, violência doméstica, 
exercícios militares, ética, legislação federal e provincial, treinamento físico, armas de fogo, operações com veículos, comunicações e uso da força.

Todos os serviços de polícia da província de Ontário realizam o treinamento básico dos seus policiais no Ontario Police College (OPC). Entretanto, algumas polícias optam por realizar outras etapas de treinamento por sua própria conta. É o caso do Ottawa Police Service. Além do curso realizado no $O P C$, a formação dos policiais de Ottawa acontece também no Professional Development Centre (PDC), responsável por mais 21 semanas de treinamento. Ao todo a formação básica do policial de Ottawa dura 33 semanas.

Tanto no Ontario Police College quanto no Professional Development Centre, a instrução dos policiais é centrada nos manuais e normas de conduta policial. A instrução de uso da força, por exemplo, é centrada na aplicação do Ontario Use of Force Model. ${ }^{10}$ Este tipo de treinamento não é realizado apenas na formação inicial dos policiais. Anualmente, todos os policiais são obrigados a passar, durante uma semana, pelo treinamento sobre o uso da força.

O Police Services Act (1990) estabelece que cada departamento de polícia da província de Ontário implemente um sistema para lidar de forma adequada com as reclamações (complaints) feitas pela comunidade. A fim de cumprir com esta exigência, o Ottawa Police Service implementou a Professional Standards Section (PSS) com a tarefa de promover a resolução destas reclamações com base nos padrões profissionais de conduta policial. Cabe a esta unidade policial investigar as reclamações, investigar todos os incidentes que envolvam disparo de arma de fogo, conduzir investigações paralelas e sugerir recomendações, com base nas reclamações recebidas, sobre mudanças no treinamento e nas normas de conduta em uso na polícia.

10 O Modelo de Uso da Força de Ontário (OUOFM) foi estabelecido em 2004 pela Associação dos Chefes de Polícia de Ontário (Ontário Association of Chiefs of Police - OACP). Trata-se de uma representação gráfica das situações potencialmente violentas. 
Além desta unidade, existe a Ontario Civilian Commission on Police Services (OCCPS). Esta comissão é o órgão de controle externo destinado a supervisionar as atividades de todos os serviços de polícia de Ontário. Além de investigar algumas denúncias de desvio de conduta policial, a OCCPS funciona também como uma instância quase judicial, servindo de corte de apelação das decisões disciplinares adotadas pelos serviços de polícia. Além dela, tanto os membros da comunidade quanto os policiais podem recorrer aos tribunais judiciais.

Existem dois tipos de reclamações: sobre os serviços e políticas implementados pelos departamentos de polícia e sobre a conduta profissional dos policiais. De forma geral, as reclamações são feitas diretamente ao Ottawa Police Service, através do seu serviço de queixas e reclamações. Uma vez recebida a reclamação, o chefe de polícia tem 30 dias para decidir como irá tratá-la. Ele pode recusá-la porque foi feita fora do prazo legal (até seis meses da data do incidente), ou porque se trata de uma reclamação sobre serviço que não é da competência da polícia ou, ainda, porque o policial acusado de desvio de conduta não pertence ao OPS. O Chefe de polícia também pode recusar uma reclamação, por julgá-la frívola ou de má-fé. Em qualquer destas circunstâncias, o(a) reclamante pode apelar a OCCPS.

Uma vez aceita uma reclamação, é instaurada investigação para avaliar as circunstâncias do incidente. Para isso, é designada uma equipe de investigadores da Professional Standards Section. Após a investigação, a PSS poderá recomendar ao chefe de polícia: a) buscar um acordo informal entre o(a) reclamante e o policial acusado (o Police Services Act sugere que as reclamações sejam resolvidas desta forma, à princípio); b) desconsiderar a reclamação por ser improcedente; c) impor pena disciplinar sem necessidade de audiência com o policial acusado, caso não se trate de sério desvio de conduta profissional e d) impor pena disciplinar, 
após audiência com o policial acusado, quando se tratar de sério desvio de conduta profissional.

Dependendo da gravidade do caso, o chefe de polícia pode encaminhar o policial para tratamento específico ou para realizar novamente determinado tipo de treinamento. Ou pode, ainda, punir o policial com multa, suspensão ou repreensão. Nos casos mais graves, o chefe de polícia pode determinar a demissão ou remoção do policial acusado de desvio de conduta profissional. Qualquer que seja o tipo de punição disciplinar, ela será incorporada nos registros pessoais do policial e terá impacto sobre sua carreira.

Nesses casos mais graves, é necessária a instalação de audiência pública (Public Hearing). Um policial, de posto igual ou superior ao do acusado, é designado para desempenhar o papel de promotor e apresentar as provas. Um outro policial, de posto superior, é designado para a função de juiz.

Em qualquer dos casos, uma acusação de desvio de conduta só poderá ser aceita se houver provas claras e convincentes sobre os fatos denunciados e se fizer referência a um estatuto legal ou administrativo infringido pelo policial acusado. As normas de condutas e as orientações administrativas desempenham um papel muito importante nestes processos. Geralmente, são elas que servem de suporte legal para a avaliação da conduta profissional dos policiais. A utilização destas normas administrativas na avaliação das condutas policiais fica evidenciada na leitura das decisões da Ontario Civilian Commission on Police Services.

Em novembro de 1999, o policial L. Turgeon foi punido com 10 dias de suspensão por uso desnecessário da força. ${ }^{11} \mathrm{O}$ policial foi acusado de agredir e ameaçar um jovem que dirigia irregularmente um veículo roubado. De acordo com a decisão da OCCPS, o policial infringiu a seção (1)

11 OCCPS, Sumary of Decision nr. 99/06 (disponível em 15/11/05 no sítio http://www.occps. ca/search_disciplinary.asp). 
(G) (i) do código de conduta policial (O. Reg. 927). Embora a prisão do jovem tenha sido legal, o policial não conseguiu justificar adequadamente os procedimentos que adotou naquele incidente. ${ }^{12}$

Para avaliar a conduta deste policial, convocou-se o Sargento Rick Keindel, instrutor do Ontario Police College, para atuar como especialista. ${ }^{13}$ Às vezes, compete a estes profissionais avaliar se as condutas adotadas pelos policiais foram adequadas, segundo as normas administrativas existentes. Nestes casos, a avaliação das condutas profissionais é realizada por um especialista da profissão.

As normas administrativas de conduta não servem apenas para proteger os direitos dos cidadãos. Elas protegem também os policiais quando lhes transmitem orientações claras de como proceder. Em março de 2003, o policial Wendy Blomfield foi inocentado da acusação de ter negligenciado os procedimentos administrativos relativos aos casos de violência doméstica. De acordo com a decisão da OCCPS, o policial seguiu adequadamente o que prescreve as Seções 2 (1) (C) (i) e (ii) das normas sobre violência doméstica (partner assault, O. Reg. 123/98).

\section{Conclusão}

Na última década, algumas polícias brasileiras procuraram criar Códigos de Deontologia. Estas iniciativas pouco melhoraram o controle da atividade policial. Este foi o caso da Policia Militar do Distrito Federal, que criou seu Código de Ética Policial em 1997.

Como esta pesquisa mostrou, os Códigos de Deontologia são genéricos, pois supostamente tratam de todas situações encontradas na rotina

12 De acordo com o modelo de uso da força em uso na província de Ontário, o policial possui discricionariedade nas suas ações, desde que justifique suas opções.

13 Entrevista com o Sargento Rick Keindel em 13/10/2005. 
policial. São também abstratos, uma vez que não fornecem orientações claras aos policiais de como proceder. É necessário complementar as diretrizes contidas nos códigos com normas administrativas de condutas, como ocorreu na província de Ontário.

A escassez de normas de conduta e a sua omissão com relação às técnicas e procedimentos tornam o treinamento pouco útil para controlar a atividade policial. Afinal de contas, só é possível treinar alguém se sabemos previamente como esperarmos que ele proceda. Do contrário, o treinamento policial específico fica restrito às aulas de tiro, ordem unida, treinamento físico e legislação penal, como na maioria das polícias militares brasileiras. Nesses casos, pouca ênfase é dada às situações de contato entre policiais e cidadãos.

Sem o estabelecimento de normas claras de conduta, não é possível adequar as técnicas de ação e o treinamento aos princípios previstos no código de deontologia. O treinamento policial é mais do que a simples transmissão de habilidades específicas. Nele também são transmitidos os valores e princípios contidos no código de deontologia. Esta ausência de normas de conduta tem sido objeto de preocupação de policiais e especialistas. Visando preencher esta lacuna, nos últimos anos algumas polícias brasileiras vêm tentando elaborar normas de conduta para determinadas situações do policiamento cotidiano. Entretanto, o processo ainda é bastante incipiente, sem uma clara articulação entre estas normas e os códigos de deontologia. 


\section{Monitoring police activity: a comparative analysis of codes of ethics in Brazil and Canada}

\section{Abstract}

In this paper we discuss police deontology and codes of ethics used in two police institutions: the Military Police of the Federal District (Brazil) and the Ottawa Police Service (Canada). First, we analyse and compare contents of these documents. Following, we examine how each of those police institutions coordinates its training and evaluation systems with its own deontological code. Finally, we find that the existence of deontolgy codes in itself, without administrative regulation, does not guarantee the appropriate control of police activities. Furthermore, we identified a need for assimilation of such codes and administrative regulations by the police training and evaluation systems.

Keywords: Police. Police institutions. Police activities. Police ethics. Behavioral codes. Deontology.

\section{Referências}

ADORNO, Sérgio. Monopólio Estatal da Violência na Sociedade Brasileira Contemporânea. In: MICELI, S. (org.) O que ler na Ciência Social Brasileira. São Paulo: ANPOCS/Ed. Sumaré; Brasília: CAPES, 2002. Vol. IV.

BANDEIRA, Lourdes; COSTA, Arthur. A Deontologia e o Controle da Atividade Policial, 2003. Trabalho apresentado no XI Encontro da Sociedade Brasileira de Sociologia. Campinas, set. 2003.

BAYLEY, David. The Police and Political Development in Europe. In: TILLY, C. (Ed). The Formation of National States in Western Europe. Princeton: University of Princeton Press, 1975.

BAYLEY, David. Patterns of Policing. News Brunwick: Rutgers University Press, 1985.

BAYLEY, David. Prefácio. In: GOLDSMITH, Andrew (ed.). Complains Against The Police: the Trend to External Review. New York: Oxford University Press, 1991.

BAYLEY, David. Police for the Future. New York: Oxford University Press, 1994. 
CANO, Ignácio. Letalidade da Ação Policial no Rio de Janeiro. Rio de Janeiro: ISER, 1997.

$\mathrm{CHEH}$, Mary. Are Lawsuits an Answer to Police Brutality?. In: GELLER, William; $\mathrm{TOCH}$, Hans. Police Violence: understanding and Controlling Police Abuse of Force. New Haven: Yale University Press, 1996.

CHEVIGNY, Paul. The Edge of Knife: police violence in the Americas. New York: The New Press, 1995.

COSTA, Arthur; MEDEIROS, Mateus. Police Demilitarisation: Cops, Soldiers and Democracy. Journal of Conflict, Security and Development, vol 2 (2), p. 25-45, 2002.

COSTA, Arthur. A Fragilidade dos Mecanismos de Controle da Atividade Policial no Rio de Janeiro, 2003. Trabalho apresentado no XIV Congresso da Associação Latino-Americana de Sociologia. Brasília, 2003, mimeo.

COSTA, Arthur. Entre a Lei e a Ordem: violência e reformas nas polícias do Rio de Janeiro e Nova York. Rio de Janeiro: Ed. FGV, 2004.

DAS, Dilip; PALMIOTTO, Michael. International Human Rights Standards: Guidelines for the World's Police Officers. Police Quarterly, vol. 5 (2), 2002.

DAVIS, Kennteh. Discretionary Justice: a preliminary inquiry. Urbana: University of Illinoys Press, 1971.

GELLER, William A.; TOCH, Hans. Police Violence: understanding and controlling police abuse of force. New Haven: Yale University Press, 1996.

GIDDENS, Anthony. As Conseqüências da Modernidade. São Paulo: Ed. Unesp, 1991.

KANT DE LIMA, Roberto et al. Violência, Criminalidade, Segurança Pública e Justiça Criminal no Brasil: uma Bibliografia. BIB, 50 (2), p. 45-123, 2000.

KLOCKARS, Gari. A Theory of Excessive Use of Force and Its Control. In: Geller, W.; Toch, H. (Orgs.). Police Violence: understanding and controlling police abuse of force. New Haven: Yale University Press, 1996.

LINT, Willem de. Regulating Autonomy: Police Discretion as a Problem for Training. Canadian Journal of Criminology, vol. 40 (3), 1998.

MESQUITA NETO, Paulo de. Violência Policial no Brasil: Abordagens Teóricas e Práticas de Controle. In: Pandolfi, D. et al. Cidadania, Justiça e Violência. Rio de Janeiro: FGV Editora, 1999.

MONJARDET, Dominique. O que faz a Polícia? São Paulo: Ed. USP, 2003. 
MUNIZ, Jacqueline et al. Resistência e Dificuldades de um Programa de Policiamento Comunitário. In: Tempo Social, 9(1), mai. 1997.

PORTO, Maria Stela Grossi. Polícia e Violência: representações sociais de elites policiais do Distrito Federal. S. Paulo em Perspectiva (número especial), revista da Fundação SEADE, vol.18/n.1/jan-mar, 2004.

PORTO, Maria Stela Grossi. Violência e Segurança: a morte como poder? In: Violência Policial: tolerância zero? Brasília: MNDH;Goiânia: UFG, 2001.

SILVA, Christyne Carvalho da. Relacionamento entre Controle Interno e Externo da Polícia Militar do Distrito Federal: motivações e perspectivas. 2008. 114f. Dissertação (Mestrado em Sociologia) - Universidade de Brasília, Brasília, 2008.

SKOLNICK, Jerome; FYFE, James. Above the Law: police and excessive use of force. New York: The Free Press, 1993.

WALKER, Samuel. Taming the System: the control of discretion in criminal justice, 1950-1990. New York: Oxford University Press, 1993.

Recebido: 07/04/2010

Aceite final: 30/07/2010 